\title{
Da marginalização ao glamour: o corpo tatuado nas redes de poder-saber e jogos de verdade do discurso midiático
}

\author{
From Marginalization to glamour: the tattooed body in \\ power-knowledge networks and truth games of media \\ discourse
}

\author{
Regina BARACUHY \\ Universidade Federal da Paraíba (UFPB) \\ Edileide GODOI \\ Círculo de Discussões em Análise do Discurso (CIDADI)
}

\begin{abstract}
RESUMO: Este artigo objetiva mostrar como o corpo tatuado sai do anonimato, da marginalidade, deixando de ser um elemento transgressor da norma social para ressignificar-se pelas lentes da mídia, ao ser discursivizado como símbolo de beleza, associado ao glamour e à sensualidade por meio de relações de saber-poder e de jogos de verdade. Para alcançar nossa meta, dividimos nosso texto em três partes: uma primeira, em que apresentamos uma breve história do corpo e seus deslocamentos ao longo do tempo para mostrar como o tatuado, ao ser normatizado pela mídia, adquire novas significações. Em seguida, discutimos sobre relações de poder e identidade para tratarmos de como se constrói o sujeito tatuado na esfera midiática. $\mathrm{Na}$ terceira e última parte, expomos como a mídia impõe para o corpo tatuado uma política de estetização, a fim de incluí-lo socialmente.
\end{abstract}

PALAVRAS-CHAVE: Corpo tatuado. Mídia. Relações de saber-poder. Jogos de Verdade.

ABSTRACT: This article aims to show how the tattooed body goes out of anonymity, marginality, ceasing to be a transgressor element of the social norm to receive new meanings through media lens, when put into discourse as a symbol of beauty, associated with glamour and sensuality through power-knowledge relations and truth games. To achieve our goal, we divided the text into three parts: the first, in which we present a brief history of the body and its movements over time to show how the tattooed subject, as it is regulated by the media, acquires new meanings. Next, we discuss relations of power and identity to deal with how is the tattooed subject build on the media sphere. In the third and final part, we expose how the media imposes one aesthetization policy in order to include the tattooed body.

KEYWORDS: Tattooed body. Media. Power- knowledge relations. Truth games

\section{Introdução}

Perseguida, proibida, estampada, escondida, estandarte de bravura, insígnia da marginalidade, sentença de morte, marca de resistência, objeto de inclusão/exclusão, amuleto de proteção, rito de passagem, roupa de luto na tribo, atestado de nascimento, documento de identidade, autobiografia, traço da cultura, desenho, escrita, status, moda, beleza, símbolo de sensualidade; a tatuagem não se refere apenas a um conjunto de técnicas corporais, mas engendra em si mesma um conjunto de significados históricos nas quais os sujeitos se produzem e são produzidos. (Le BRETON, 2004).

Encorajada aqui, proibida ali, ela independe da geografia, classe ou calendário e é tão antiga quanto a própria humanidade. Nasce e renasce em todos os continentes de modo espontâneo, aos saberes dos grandes deslocamentos humanos, "seguindo 
(escrevendo) a história de vencedores e de vencidos, dos reis e dos súditos, dos indivíduos do gelado ártico aos marinheiros de Santos.” (MARQUES, 1997, p.35)

Em diferentes épocas e lugares do mundo, o homem usou e continua a usar a tatuagem como forma de comunicação, seja para demonstrar sentimentos ou crenças, seja para fins de adornos ou para marcar um lugar em determinada comunidade, ou ainda para demonstrar ritos de passagem ou forma de identificação.

Devido aos avanços tecnológicos associados à necessidade da troca de informação, criou-se um ambiente favorável para que os meios de comunicação se ampliassem e tomassem um lugar central e influente na sociedade. Em decorrência disso, acompanhamos o surgimento de uma nova produção da subjetividade, na qual as experiências e relações são arroladas pela mídia.

Numa sociedade pós-moderna em que se configuram identidades fluidas, relações líquidas e uma cultura narcisística de exaltação gloriosa ao corpo, a mídia se apresenta como o lugar para o espetáculo e afirmação da aparência.

\section{Do corpo anormal à normatização do tatuado na mídia}

Em nossa sociedade, a norma é cada vez mais ligada a mecanismos de disciplinarização, correção e vigilância que direcionam a vida e o corpo do sujeito, ou seja, os processos de nominação e separação entre o sujeito normal e o anormal são definidos por mecanismos responsáveis por adequar o corpo a uma ordem sociocultural.

Segundo Foucault (2001), o conceito de anormal de nossos dias vem do final do século XVIII, sendo derivado das relações de reciprocidade que se estabeleceram entre três figuras distintas inaceitáveis socialmente: o monstro moral, o indivíduo a corrigir e o onanista. Todos marcados por dois elementos: o jurídico e o biológico.

A primeira categoria, o monstro moral, "combina o interdito e o impossível". As malformações passaram a ocupar lugar de destaque na medida em que subverteram a lei natural, as leis da sociedade e da justiça. A periculosidade de monstro moral conduz a inversão do crime monstruoso, ao monstro criminoso (Foucault 2001, p.128). A segunda categoria, o indivíduo a corrigir é uma personagem mais recente do eu monstro. "É o mais correlato das técnicas de adestramento, com suas exigências próprias, do que dos imperativos da lei e das formas canônicas da natureza. $\mathrm{O}$ aparecimento do incorrigível é contemporâneo ao estabelecimento das técnicas de disciplina, a que se assiste durante os séculos XVII e XVIII" (FOUCAULT, 2001, p. $63)$.

A última categoria, do onanista, a criança masturbadora, é a mais nova. Surgiu em meados do século XIX e foi contemporânea ao desenvolvimento das teorias da sexualidade infantil e às teorias da psicopatologia das perversões. Tais teorias transportaram-se das práticas de confissão da Reforma Protestante e o seu policiamento dos pecados, entre os quais o desejo sexual. O saber-poder médico conquista definitivamente o seio das famílias, normatizando, controlando e regulando a relação entre pais e filhos. O médico herda o papel do padre: em lugar de interrogatórios, consultas; em lugar de penitências, tratamentos e conselhos. Como descreveu Foucault (2001, p. 74), "a pequena família incestuosa que caracteriza nossas sociedades, o minúsculo espaço familiar sexualmente saturado em que somos criados e em que vivemos formou-se aí".

Em todas as categorias, o filósofo evidenciou histórias e trajetórias autônomas. Contudo, suas especificidades se modificaram e se misturaram em convergências e deslizamentos. Desse modo, a genealogia dos anormais se formou a partir do 
estabelecimento de uma rede regular de saber-poder, que sustenta o conceito de anormal.

Conforme Foucault (2001), existe uma norma cultural cuja exigência postula que o sujeito seja ou não de determinada forma, esteja ou não dentro de uma determinada ordem, e esse tipo de ordem é marcada pelo/no corpo. Para esse filósofo, o corpo é o lugar de constituição do indivíduo, onde se travam as relações de saber-poder, lugar sobre o qual atuam os discursos e práticas sociais.

Em "Vigiar e Punir" (1975), o corpo aparece como um produto, um objeto infinitamente maleável do poder. A fabricação de corpos dóceis fabricados e governáveis é o alvo das disciplinas. Entretanto, é importante pensar que as formas de subjetividade almejadas na contemporaneidade não podem ser apenas vinculadas às singularidades somáticas das disciplinas, mas às lógicas das relações de poder em que governar pressupõe a legitimação do outro, a aceitação dos governados e, sobretudo, a possibilidade de resistência, embora segundo Ortega (2008), no processo de constituição de si, encontramos nas práticas de bioascese ${ }^{1}$ pós-modernas, uma vontade de uniformidade, de adaptação à norma e a constituição de modos de existência conformistas que visam à saúde e ao corpo perfeito.

Nessa mesma direção, Pereira (2013, p.173) salienta que atualmente se pode visualizar um movimento incessante de procura de apagamento das marcas das diferenças em favor da construção de um mundo harmônico e que, por isso, "busca-se desativar o que difere, marcando com uma identidade anormal o que burla, desenquadra, rompe, destoa dos enclausurados parâmetros de normalidade que engessam os sujeitos e seus corpos".

Retomando mais uma vez Ortega (2008, p.48), ele diz que os avanços tecnológicos e científicos direcionados ao corpo a partir do século $\mathrm{XX}$, tornaram as modificações corporais, um fato especial na tentativa de personalização do sujeito, pois

não podendo mudar o mundo, tentamos mudar o corpo, o único espaço que restou à utopia, a criação". Body-building, tatuagens, piercings, transplantes, próteses, clonagem, e até mesmo a última moda das amputações voluntárias representam avanços na conquista do último continente, o corpo, com as tentativas de personalizá-lo.

A tatuagem tem suas particularidades influenciadas pelos valores sociais, culturais e temporais da sociedade na qual está inserida. Para Foucault (2004), os sujeitos precisam ser compreendidos como sendo produzidos em locais históricos e institucionais específicos, porque eles são construídos dentro e não fora dos discursos.

Buscando compreender como a mídia produz discursos que justificam a exclusão/inclusão de determinado sujeito tatuado, acreditamos que isso ocorre em decorrência de uma regra sociopolítica que vai classificar os indivíduos em normais e anormais, inseridos em regimes de verdade que buscam governar e direcionar a vida e os corpos dos sujeitos.

O corpo, cujas formas causam mal-estar social, é o corpo transgressor, é o corpo desgovernado dos sujeitos, que subverte uma ordem pré-estabelecida, seja dada sócioculturalmente, seja fixada pelas leis da natureza, acusando lugares para o impossível e para o proibido.

\footnotetext{
${ }^{1}$ Ortega (2008) salienta diferencia as práticas de ascese clássicas das de bio-ascese contemporâneas Enquanto estas são entendidas como práticas de "assujeitamento e disciplinamento", as práticas ascéticas da Antiguidade representavam práticas de liberdade, de cuidado de si, pois transformavam o modo de ser do sujeito. Foucault (1984) entende a ascesce a partir das práticas de si.
} 
Le Breton (2010, p.64) salienta que, em relação ao discurso estético, a transgressão está na deformação, no estranho, em corpos como o do Frankenstein, que é o corpo de vida e de morte ao mesmo tempo. Para o autor, esse corpo transgride os limites do simbólico e de todas as leis que permitem nomeá-lo, classificá-lo, identificálo. Nas palavras do autor, "a condição do homem é corporal. Subtrair-lhe alguma coisa ou lhe acrescentar, coloca esse homem em posição ambígua, intermediaria. As fronteiras simbólicas são rompidas [...] toda modificação de sua forma engaja outra definição de sua humanidade".

Os sujeitos tatuados, que são considerados anormais no sentido foucaultiano do termo, são justamente aqueles que provocam uma ruptura na manutenção da ordem social. Por exemplo, não é toda ou qualquer tatuagem que os militares querem barrar na Marinha e no Exército, mas apenas aquelas que são consideradas extremistas e/ou violentas, ou seja, as que desestruturam a ordem imposta por um poder governamental. Desse modo, o sujeito que deseja ingressar ou já segue a carreira da Marinha do Brasil não pode fazer ou ter a tatuagem que quiser e onde quiser, porque é preciso se submeter à ordem do discurso militar.

Os corpos anormais, além de serem discriminados, terminam frustrados por não serem capazes de atingir o ideal socialmente imposto. Para serem socialmente aceitos, os sujeitos sentem necessidade de se incluírem na ordem de nossa sociedade midiática.

Portanto, a mídia atua como dispositivo normalizador que inclui/exclui os sujeitos tatuados ao adotar uma positividade que se liga a práticas sociais verdadeiras de uma época. Assim, a prática da tatuagem discursivizada pela mídia passa pela positividade da normalização através dos discursos jurídico, médico e estético, a exemplo das leis que regularizam a prática da tatuagem propondo uma idade mínima; o discurso médico que impõe o uso de produtos descartáveis para a perfuração da pele e ainda o discurso estético, que (res)significa o corpo desenhado, tatuado, como sendo bonito, sensual, fashion e "estiloso".

\section{Relações de poder e Identidade: quem é o sujeito tatuado da mídia?}

A circulação de imagens, valores, referências simbólicas, torna a mídia uma poderosa ferramenta formadora de opiniões, saberes, normas e subjetividades. Utilizando-se de manobras estratégicas, a mídia faz com que um grande contingente de pessoas veja o mundo por suas lentes, seus vieses. Para Kellner (2001, p.09):

Há uma cultura veiculada pela mídia cujas imagens, sons e espetáculos ajudam a urdir o tecido da vida cotidiana, dominando o tempo de lazer, modelando opiniões políticas e comportamentos sociais, e fornecendo o material com que as pessoas forjam sua identidade. O radio, a televisão, o cinema e outros produtos da indústria cultural fornecem modelos daquilo que significa ser homem ou mulher, bem sucedido ou fracassado, poderoso ou importante. A cultura da mídia também fornece o material com que muitas pessoas constroem seu senso de classe, de etnia e raça, de nacionalidade, de sexualidade, de 'nós' e 'eles'. Ajuda a modelar a visão prevalecente de mundo e os valores mais profundos: define o que é considerado bom ou mal, positivo ou negativo, moral ou imoral.

A mídia é um espaço de circulação das normas sociais e culturais vigentes de representação do sujeito. Este, na ausência de grandes referências nas quais se apoiar, vincula à mídia sua possibilidade de acesso ao mundo e de construção de laços sociais. 
Logo, a questão da representação, que circula nos meios de comunicação, emerge no processo de constituição do sujeito. Enquanto prática de significação, a representação envolve relações de saber-poder direcionadas a governar a vida das pessoas, sobretudo é o poder-saber que define quem é incluído e quem é excluído. Nas palavras de Woodward (2003, p.17):

A representação inclui as práticas de significação e os sistemas simbólicos por meio dos quais os significados são produzidos, posicionando-nos como sujeito. É por meio de significados produzidos pelas representações que damos sentido a nossa experiência e àquilo que somos. Podemos inclusive sugerir que esses sistemas simbólicos nos quais ela se baseia fornecem possíveis respostas às questões: Quem sou eu? O que eu poderia ser? Quem quero ser? Os discursos e os sistemas de representação constroem os lugares a partir dos quais os indivíduos podem se posicionar e a partir dos quais podem falar.

Considerando ainda que as identidades são formadas socialmente por sistemas de diferença, ou seja, me constituo a partir do lugar de onde não sou, as representações dão sentido às desigualdades sociais, justificando a exclusão e estigmatizando alguns grupos.

Como produtora e reprodutora de práticas sociais, a mídia faz reverberar esses discursos e propõe aos sujeitos tatuados, modos de expor o corpo que normatizam as construções identitárias dos tatuados e modificam os processos de subjetivação desses sujeitos. Entretanto, isso não significa que as propostas da mídia sejam todas negativas, pois "a norma não tem por função excluir, rejeitar. Ao contrário, ela está sempre ligada a uma técnica positiva de intervenção e de transformação, uma espécie de poder normativo" (FOUCAULT, 2001, p. 43), que interfere na produção de identidades.

No caso da normatização da tatuagem, a positividade está em manter a ordem, a saúde física e o bem estar do sujeito que se tatua. No entanto, as construções identitárias atuais dos tatuados e de outros sujeitos que destoam do padrão do corpo ideal têm o mesmo efeito de marcar negativamente e excluir esses corpos alheios à norma.

Observamos que, em um curto intervalo de tempo, a tatuagem ganhou visibilidade e o corpo se tornou ícone de novos modelos estéticos, nas ondas do mar, nas pistas de dança, nas telas da TV, nas capas das revistas e nas passarelas da moda. A aparência doravante alimentaria uma indústria sem fim.

Segundo Courtine (2009, p. 10), nunca, antes do século XX, o organismo foi tão penetrado antes pelas tecnologias da medicina, jamais o corpo conheceu uma superexposição tão obsessiva, jamais as imagens das brutalidades sofridas pelo corpo nos campos de concentração durante a Segunda Guerra tiveram equivalente em nossa cultura visual. Do corpo nascem e se propagam as significações que fundamentam a existência do sujeito e suas identidades.

A importância dada ao corpo e ao que a ele se refere só ganham ênfase a partir de novas tecnologias desenvolvidas para o corpo, principalmente a partir do século XX, De acordo com Sant'Anna (2005, p.115), após os movimentos sociais da década de 1960, sobretudo na Europa e nos Estados Unidos, o corpo foi redescoberto na arte e na política, na ciência e na mídia, fazendo emergir determinadas práticas corporais: 
$\mathrm{O}$ século XX apresentou um novo conceito de corpo e estabeleceu outro espaço de representação do corpo na sociedade. A valorização de um foco que associa estética à beleza, fez com que o corpo passasse a ser visto na perspectiva de um modelamento corporal, promovendo um culto ao corpo, que envolve as relações e intervenções na busca de um padrão idealizado cultural e socialmente.

No entender dessa autora, os valores corporais e padrões de comportamento e beleza sobre o corpo são construídos a partir de práticas socioculturais que mudam de uma época a outra. Sendo que hoje, esses valores ganharam a visibilidade pelas lentes da mídia que, de um modo geral, tem como pretensão vender uma ideia ou produto, o que faz com que ela sempre enuncie algo positivo, desejável e ideal. Uma prática de poder que inclui sujeitos com base em padrões normalizadores específicos e, ao mesmo tempo, exclui aqueles que não estão dentro desses padrões modelares. Contudo, essas proposições não são elaboradas à base do que é proibido, você não deve, você não pode, ao contrário por outro modalizador, você pode, você consegue, "mais tattoos, menos inocência"; "seu corpo é seu diário".

No Brasil, nas décadas de 1970 e 1980, o discurso midiático propunha, por meio de revistas, da música, da moda, uma forma de ser e de estar na vida, ao perceber o fascínio dos jovens pela tatuagem, tendo em vista que ela representava o fim da centralização dominante e o desejo de gerir seus próprios corpos.

Diferentes tribos e classes sociais começaram a se tatuar. $\mathrm{O}$ corpo se torna um território. Gestos, atitudes, roupas e interferências como o "body building", a tatuagem e o piercing são apropriações ideológicas do corpo. Era o desejo de se representar que ganhava o direito de construir certas identidades sobre quem eram e quem deveriam ser.

A identidade passava a ser marcada pelas frases emblemáticas estampadas nas camisetas ("I Love" com o verbo em forma de coração), pelas imagens dos cantores de rock pintadas nas camisas, pelas frases pichadas nos muros, pelos desenhos tatuados na pele. "A vida virou um tiroteio de declarações móveis, um infinito diálogo de espelhos ambulantes." (MARQUES, 1997, p.188). Eles pichavam as paredes, assinavam os locais, exibiam suas revoltas, mas logo perceberam que os muros e as calçadas eram de todos e o que é de todos não é de ninguém. Passaram assim, "das paredes da cidade à pele da vida, o caminho era estreito e o corpo tornou-se, nos anos 70, o suporte da assinatura pessoal" (Le BRETON, 2004, p 75).

Negando a massificação capitalista, criava-se um estilo de vida, de comer, de beber, de vestir, mas, principalmente, de habitar o corpo. Desse modo, o estilo de vida adotado pelos grupos da contracultura (hippies, punks), que rompia com a hegemonia do discurso midiático, entrava nas redes da mídia ressignificado como tendência fashion pelo discurso da moda, que lançava representações esteticamente aceitáveis (corpo magro, tatuado, malhado, vestido pela roupa de grife) para serem decodificadas e adotadas conforme o sistema simbólico cultural vigente.

No final da década de 1970 e início dos anos 1980, a mídia buscava construir um sujeito disciplinado que podia ser "radical", dono do seu corpo, que fazia suas escolhas, mas não rompia com ideais, enquanto cidadão (sujeito político que cumpria as leis) através de um conjunto de enunciados que colocava em voga a constituição de um sujeito tatuado descolado, "diferente", submetido a manobras de exposição do corpo, sem fugir das verdades sociais vigentes.

$\mathrm{Na}$ ótica de Marques (1997), esse movimento midiático ocorre, sobretudo, porque as classes média e média alta passaram a usar a tatuagem como marca de ornamentação, símbolo de suas aspirações, suas conquistas e seus desejos, fazendo do corpo, um espaço de seu domínio. Tais classes, vistas como aquelas que seguem as 
normas, criam padrões jurídicos, éticos, não poderiam correr o risco de serem taxadas de marginais nem principalmente serem vítimas de preconceito. Com isso, era preciso vender e criar uma ideia diferente da que circulava na época: tatuagem, sinônimo de marginalização.

Sobre isso, é interessante refletir ainda que, se a tatuagem era incorporada às práticas corporais de visibilidade social, de certa forma, esse poder também tirava da exclusão, a classe marginalizada, pois se aquela passava a ser usada por qualquer classe social, entrando nos discursos verdadeiros da época, como dizer quem era ou não marginal. Essa questão não foi, e não é, ainda hoje, tão simples assim. A tatuagem em nossa sociedade nunca deixou de ser vista como um símbolo de exclusão social, de marginalização. Por isso, as instituições de poder, como a polícia e a mídia, logo pensaram em outros meios, criaram novas práticas, novas ordens para diferenciar os sujeitos marginais daqueles não marginalizados.

A mídia instituiu mecanismos sutis para fazer essa divisão através de propagandas e telenovelas, por exemplo. Já a polícia usava a tatuagem como meio simbólico para detectar e punir o sujeito que rompia com a ordem social, fortalecendo ainda mais esse recurso com o uso de cartilhas sobre os sentidos possíveis para as tatuagens marginais e com a reverberação desses significados por toda a corporação através de treinamentos.

Nessa perspectiva de representação sociocultural, as instituições de poder como a polícia e a mídia agem com eficácia. Para Gregolin (2003b, p.97), as instituições são construtoras de imagens simbólicas e como tal "participam ativamente da construção do imaginário social, no interior do qual os indivíduos percebem-se em relação a si mesmos e em relação aos outros. Dessa percepção vem à visualização do sujeito como parte dessa coletividade".

Baronas (2003, p.88) salienta que "por intermédio de complexo processo de criação de necessidade dos/nos sujeitos, a mídia, nos seus mais diversos suportes, intervém na sociedade, disseminando normas de conduta que seriam capazes de suprir essas necessidades nos/dos sujeitos" e na medida em que atrai expectadores, vende mercadorias que são oferecidas aos sujeitos como necessidade.

No caso da tatuagem, cria-se o desejo de ser bonito, ter status, estar na moda, ser sexy. O que a mídia vende, na verdade, não é um produto, mas a possibilidade de uma forma de ser; ela cria subjetividades, propondo e impondo ao sujeito como se fossem mercadorias.

$\mathrm{Na}$ sociedade contemporânea, a vontade de transformar seu próprio corpo tornou-se um lugar comum. "Já não se trata de se contentar com que se tem, mas de modificar os seus fundamentos para completá-lo ou torná-lo conforme a ideia de que se faz dele". (Le BRETON, 2004, p. 30) E a tatuagem, vista como uma técnica que pressupõe escolhas pessoais e desenhos que podem ser criados com exclusividade para o indivíduo, é uma forma significativa desta mudança de relação com o corpo.

"O ritual da tatuagem contemporânea surge nas vivências e experiências metropolitanas modernas marcadas pela diferença" (RAMOS, 2001, p.57). Perez (2005) defende que hoje se investe na subversão dos valores, do status, da moda, da beleza e do lugar sociocultural que tem caracterizado o exercício dessa prática por meio dos seus três componentes básicos: o tipo de usuário (antes restrito a uma população marginal e agora abrangendo todas as classes sociais), o perfil do tatuador (de amador a profissional) e o caráter da tatuagem (de estigma à obra artística). 


\section{A política midiática de estetização do corpo: tatuagem e jogos de verdade}

Para Courtine (2009), com o processo de industrialização e a revolução tecnológica crescente a partir do século XIX, o corpo se torna um dos principais textos do Capitalismo ocidental e deve se modificar e se adequar às necessidades de produção, configurando suas formas a partir dos processos biotecnológicos, ou seja, as tecnologias direcionadas ao corpo transformam os hábitos das pessoas e, consequentemente, seus corpos.

Ao tratar da singularidade do corpo no século XX sob "as mutações do olhar", o autor acima citado salienta também que:

Jamais o organismo foi tão penetrado antes como vai sê-lo pelas tecnologias de visualização médica, jamais o corpo íntimo, sexuado, conheceu uma superexposição tão obsessiva, jamais as imagens das brutalidades sofridas pelo corpo na guerra e nos campos de concentração tiveram equivalente em nossa cultura visual, jamais os espetáculos de que foi objeto se aproximaram das reviravoltas que a pintura, a fotografia, o cinema contemporâneos vão trazer à sua imagem (COURTINE, 2009, p. $10-11$ ).

Na verdade do século XX, com os avanços tecnológicos em torno da exploração visual, apresentou-se um novo conceito e se estabeleceram outros espaços de representação do corpo na sociedade:

A valorização de um foco que associa estética à beleza fez com que o corpo passasse a ser visto na perspectiva de um modelamento corporal, promovendo um culto ao corpo, que envolve as relações e intervenções na busca de um padrão de beleza idealizado cultural e socialmente. (PERREIRA, 2013, p. 115).

No processo histórico, determinado padrão de beleza se torna idealizado e atrai a visibilidade através de uma constante divulgação pelas lentes midiáticas. Ainda segundo Pereira (2013), a mídia atua com eficiência na supervalorização da aparência corporal e promove a busca constante do corpo ideal, estimulando o desejo a esse corpo e as formas de consumo que nos aproximam dele.

Levando em conta a circulação da prática da tatuagem nos meios de comunicação de massa, observamos duas posições-sujeito que estão no centro dos discursos reproduzidos na mídia: ora uma posição ideologicamente constituída, associada à classe média e à classe média alta, visando à produção de verdade sobre como e em que corpo e local deve estar a tatuagem, ou seja, produz uma verdade sobre o corpo e um controle dos indivíduos tatuados; ora se posiciona com um olhar negativo para essa prática, na medida em que cria efeitos de sentidos que reverberam, mostrando não ser qualquer corpo tatuado de qualquer sujeito, que sai do anonimato para atrair olhares nos mais variados espaços público, não é qualquer sujeito tatuado que obtém concessão para exibição positiva, mas um sujeito cujo corpo não pertença a um lugar social marginalizado, um corpo esteticamente bonito e jovem: malhado, magro, "plastificado".

Sobre isso Baracuhy e Pereira (2012, p.33) afirmam que 
Um corpo belo e jovem é um imperativo de uma cultura que impele os corpos à exibição e pressupõe um ideal de juventude, saúde e beleza. Aos corpos que não se enquadram nos modelos normativos, fabricados pela publicidade, moda e indústria de cosméticos, perpassam sentimentos de culpabilidade e inadequação. Na busca por um corpo perfeito, são intensificados os processos de controle e disciplinamento do corpo.

Assim, a tatuagem, situada em um espaço de positividades, entra na ordem do discurso publicitário, a partir do século XX, não como a tatuagem dos "infames", dos sem classe, mas como a tatuagem das atrizes e atores, dos cantores e cantoras, dos modelos, dos jovens adeptos a prática esportiva, a procedimentos médicos estéticos, a indústria de cosméticos. E o que estiver fora desses padrões está fora dos regimes de verdade da época.

Aqui no Brasil, essas representações positivas e negativas em relação à tatuagem podem ser constatadas e entendidas a partir da década de 1980 em novelas e propagandas que exibiam e estimulavam a classe média urbana a se tatuar. Por exemplo, na novela "Guerra dos sexos" (1983), exibida pela Rede Globo, o ator Mário Gomes tinha tatuado no peito uma gaivota cruzando um sol. Ele representava o mocinho rico, bonito e descolado. Fato que obrigou "todas as lojas de tatuagem a produzirem uma quantidade incalculável de réplicas dessa tatuagem telenovelesca” (MARQUES, 1997), pois se faziam filas nos estúdios para marcar na pele a tatuagem proposta pela novela. Dessa forma, a mídia não apenas narra fatos, conta histórias ou expõe acontecimentos e sujeitos, mas os constituem.

Da novela, a prática ganhou as telas do cinema em "Garota Dourada" (1984). Neste filme, o personagem vivido por Alexandre Frota tinha tatuado no lado de fora do braço, uma gaivota e um sol. Numa cena de praia, esse personagem se vangloria dos bíceps e da tatuagem. Aqui o sujeito é proposto a partir de uma representação esteticamente bem aceita (corpo jovem e atlético) que frequenta academia e a praia, construindo mais uma vez uma representação positiva para a prática da tattoo.

Os jogos enunciativos entre bom e ruim, positivo e negativo, que são construídos midiaticamente em torno da tatuagem, vão neutralizando seu potencial de subversão, forjando um consenso, que dialeticamente destrói a rede de contra-discursos, pois conforme Gregolin (2003b, p.108) "na era da informação ininterrupta e em tempo real (grifo da autora), as técnicas de disciplina e vigilância são sofisticadas ao ponto de exigirem reordenamentos discursivos", criando novas formas de apelo e de constituição do imaginário social em que a própria resistência se transforma em mercadoria a ser insistentemente (re)produzida e transformada em discurso, neutralizando seu potencial de subversão.

Para Foucault (2010), a produção discursiva é alimentada por uma vontade de verdade que opõe o verdadeiro ao falso. Para ele não há uma verdade, mas "vontades de verdades" que se transformam de acordo com as eventualidades históricas. De acordo com Revel (2005, p.86), Foucault salienta ainda que:

trata-se de reconstituir uma verdade produzida pela história e isenta de relações de poder, identificando ao mesmo tempo as coerções múltiplas e os jogos, na medida em que cada sociedade possui seu próprio regime de verdade, isto é "os tipos de discursos que elas acolhem e fazem funcionar como verdadeiros; os mecanismos e as instâncias que permitem distinguir os enunciados verdadeiros ou falsos, a maneira como uns e outros são sancionados; as técnicas e os procedimentos que são valorizados para obtenção da verdade; o estatuto daqueles que têm o poder de dizer aquilo que funciona como verdadeiro". 
Nesse sentido, a linguagem midiática, fundamentada em um princípio de "verdade", exercita um controle ao relacionar seus enunciados a uma determinada realidade, oferecendo uma construção a seu leitor que permite produzir formas simbólicas da sua relação com a realidade social.

$\mathrm{Na}$ atualidade, novos procedimentos de poder entram em jogos de verdades não pelo direito, mas pela técnica; não pela lei, mas pela normalização; não pelo castigo, mas pelo controle, que se exercem e se extravasam do Estado e de seus aparelhos para a a população, estando disseminados nas microrrelações mais cotidianas. Para Foucault (1988, p.104), vivemos em uma sociedade em que as verdades são construídas nas correlações de forças múltiplas que se formam e atuam nos aparelhos de produção, nas famílias, nos grupos restritos e instituições que servem de suporte a amplos efeitos de clivagem que atravessam o conjunto do corpo social.

Os procedimentos corporais nas suas formas mais variadas de aplicação, podem ser entendidos como uma dupla dobra, como a define Deleuze (1996), pois, além de serem o produto de uma biopolítica, são simultaneamente, "linhas de fuga" ou pequenas transgressões do tempo presente, visto que talvez hoje não sejam mais possíveis as grandes transgressões. Segundo Pereira (2012, p.188), "nossos corpos são, ao mesmo tempo, técnicas 'quase autônomas' de individuação, assim como também são resultado de técnicas totalizantes das estruturas de controle contemporâneo."

Em relação ao corpo tatuado, observa-se o controle fundamentado nas disciplinas dos biopoderes, que normatiza tal sujeito, tal como vem acontecendo nas últimas décadas, especialmente com a incessante divulgação de uma política midiática de estetização do corpo, que deve ser jovem, bonito e sensual. Por outro lado, também se registra um processo de subjetivação do corpo individual (governo de si) que, muitas vezes, foge às regras da biopolítica midiática.

\section{Para efeito de conclusão}

Consideramos que a prática da tatuagem é marcada pela normatização do discurso da mídia por meio de regimes de verdade forjados nas (ou por) relações de poder/ saber. Segundo Foucault (1979, p.180), embora estejamos submetidos à verdade, o poder sempre abre brechas para a resistência, pois se ele fosse uma via de mão única, não haveria necessidade de uma disciplinarização. "Somos julgados, condenados, classificados, obrigados a desempenhar tarefas e destinados um a certo modo de viver ou morrer em função dos discursos verdadeiros que trazem consigo efeitos específicos de poder". Por outro lado, para compreender em que consistem as relações de poder, é necessário analisar as formas de resistência, as lutas que colocam em questão o estatuto do indivíduo, vendo onde elas se inscrevem, descobrir seus pontos de aplicação e os métodos que elas utilizam.

Veyne (2011, p.169) afirma que o discurso é o passo de comando que reprime, persuade, organiza; é o ponto de interseção, de atrito, eventualmente de conflito entre as regras e os indivíduos. "Seus efeitos sobre o conhecimento podem ser assim verdades estabelecidas sobre os efeitos de poder".

O que Foucault propõe como verdade são os jogos de verdade, isto é, as regras segundo as quais um discurso é legitimado ou não. Tais verdades são disseminadas sobretudo pelos discursos científicos, médicos, júridicos e pelas instituições, que as transmitem sob o controle, não exclusivo, mas dominante de aparelhos políticos e econômicos. Esse lugar de verdade é o de enfrentamentos, de batalhas, de debates sob a forma de lutas ideológicas. 
O processo de subjetivação em torno da tatuagem passa por uma estética da existência; um exercício em que o indivíduo procura se elaborar, se transformar e atingir um determinado modo de ser e de agir; um ethos que se constitui a partir da possibilidade de escolher a técnica de tatuar, o local no corpo, o desenho, multiplicando as significações e também, sua identidade. No entanto, essas escolhas não o libertam das regras de normalização jurídicas, estéticas ou médicas a que a prática da tatuagem está submetida, assim como não o livra da moral que regula os corpos modernos.

Em suma, o sujeito tatuado se constitui no movimento da resistência, inerente às relações de saber-poder, com o eterno afã do governo do seu corpo e o desejo de se incluir e ter visibilidade social pela normatização midiática que sutilmente o assujeita e disciplina.

\section{Referências}

ARAUJO, Leusa. Tatuagem, Piercings e outras mensagens do corpo. São Paulo, Cosac Naify, 2005.

BARONAS, R. L. A língua nas malhas do poder. In; GREGOLIN, M. R. (org). Discurso e mídia: a cultura do espetáculo. São Carlos: Claraluz, 2003 p. $83-91$.

COURTINE, J. J.; O corpo inumano. In: CORBIN, A.; COURTINE, J. J.; VIGARELLO, G. (Org.). A História do corpo: Da renascença às Luzes. Petrópolis: Vozes, 2009. v. 1, p. 487-503.

FOUCAULT, M. Microfísica do poder. Tradução de Roberto Machado. 14 ed. Rio de Janeiro: Edições Graal, 1979.

.História da sexualidade 1: a vontade de saber. Rio de Janeiro: Graal, 1988.

Aula de 22 de janeiro de 1975. In; FOUCAULT, M. Os anormais. Curso no College de France (1974-1975) Tradução: Eduardo Brandão - São Paulo: Martin, Fontes. 2001.

A Hermenêutica do sujeito. São Paulo: Martins Fontes, 2004.

A ordem do discurso. 20ed. São Paulo: Loyola, 2010.

2009.

Vigiar e punir (1975): história da violência nas prisões. 5 ed. Petropólis: Vozes,

GREGOLIN, M.R. (org). Discurso e mídia: a cultura do espetáculo. São Carlos, SP: Claraluz, 2003a.

M.R. (org). Análise do Discurso: as materialidades do sentido. 2 ed. São

Carlos, SP: Claraluz, 2003b.

GREGOLIN, M.R. Análise do Discurso e Midia: a (re)produção de identidades, In: Comunicação, mídia e consumo. São Paulo v o 1.4 n . 11 p. 11 - 25. nov. 2007

HALL, Stuart. Quem precisa da identidade? In: SILVA, T. T. da (Org.). Identidade e diferença. 2. ed. Petrópolis, RJ: Vozes, 2003, p. 103-133.

Le BRETON, D. Sinais de identidade: tatuagens, piercings e outras marcas. Trad.Tereza Frazão, 1 ed., março, 2004.

. A sociologia do corpo. 4 ed. Rio de Janeiro: Vozes, 2010

KELLNER, Douglas. A cultura da Mídia - estudos culturais: identidade e política entre o moderno e o pós-moderno. Tradução de Ivone Castilho Benedetti. Bauru, SP: EDUSC, 2001.

MARQUES, T. O Brasil tatuado e outros mundos. Rio de Janeiro: Rocco, 1997.

ORLANDI, Eni P. À flor da pele: indivíduo e sociedade. In: MARIANI, Bethânia (Org.). A escrita e os escritos: reflexões em análise do discurso e psicanálise. São Carlos: SP, Claraluz, 2006, p. 2130.

ORTEGA, Francisco. O corpo incerto: corporeidade, tecnologias médicas e cultura contemporânea - Rio de Janeiro: Garamond, 2008. 
PEREIRA, T.M.A.; BARACUHY, Regina. O insustentável peso do corpo gordo. In: Os sentidos (des)velados pela linguagem. SIMONE, Leão, LEANDRO, Maria, PEREIRA (orgs). João Pessoa. Ideia, 2012.

PEREIRA. T.M.A. O espetáculo de imagens na ordem do discurso midiático: o corpo em cena nas capas da revista Veja. 203 f. Tese (doutorado em Linguística) Programa de Pós-graduação em Linguística, Universidade Federal da Paraíba, João Pessoa, 2013.

PERES, A.Clark; PEIXOTO, S. Alves; OLIVEIRA, S.M. Pessoa (orgs). O estilo na contemporaneidade - Belo Horizonte, 2005.

PIRES, B. F. O corpo como suporte da arte: piercing, implante, escarificações, tatuagem. Editora SENAC. São Paulo, 2005.

RAMOS, C. M. A. Teorias da tatuagem: corpo tatuado: uma análise da loja Stoppa Tatoo da Pedra . Florianópolis: UDESC, 2001.

SANT'ANNA, D. Bernuzzi. Políticas do corpo: elementos para uma história das práticas corporais. Tradução: Mariluce Moura, 2 ed. São Paulo, Estação liberdade 2005. REVEL, Judith. Foucault: conceitos essenciais. São Carlos: ClaraLuz, 2005.

VEYNE, Paul. Foucault: seu pensamento, sua pessoa. Trad. Marcelo Jacques de Morais. Rio de Janeiro: Civilização Brasileira, 2011.

WOODWARD, Kathryn. Identidade e diferença: uma introdução teórica e conceitual. In: SILVA, T. T. da (Org.). Identidade e diferença: a perspectiva dos Estudos Culturais. 2. ed. Petrópolis, RJ: Vozes, 2003, p. 7-72. 